\title{
RENTABILIDADE E RISCO NA ESTOCAGEM DO CAFÉ PELOS PRODUTORES NA REGIÃO DE VIÇOSA-MG ${ }^{1}$
}

\author{
Alan Figueiredo de Arêdes ${ }^{2}$ \\ Matheus Wemerson Gomes Pereira ${ }^{3}$ \\ Vladimir Faria dos Santos ${ }^{4}$ \\ Maurinho Luiz dos Santos ${ }^{5}$
}

\begin{abstract}
Resumo - O objetivo deste artigo foi avaliar a rentabilidade e o risco na estocagem do café arábica na região de Viçosa-MG. Para isso, elaboraram-se os fluxos de caixa para a cultura do café em dois sistemas produtivos, um com baixa produtividade e outro com alta produtividade, em doze diferentes cenários, em que cada um representava os retornos e riscos na estocagem da safra, em cada mês do ano. De acordo com os indicadores financeiros, Período de Payback (PP), Valor Presente Líquido (VPL) e Taxa Interna de Retorno (TIR), e o indicador Custo Médio (CMe), a elevação da produtividade do cafezal, pela adoção de maiores níveis de insumo, e a estocagem do café são importantes condicionadores para elevação da rentabilidade e diminuição do nível de risco da atividade, e os melhores períodos para a venda do produto, por parte dos produtores, são os meses que antecedem a safra, ou seja, janeiro, fevereiro e março, respectivamente.
\end{abstract}

Palavras-chaves: café, rentabilidade, risco.

Recebido em: 17/03/08; Aceito em: 26/06/08.

2 Doutorando em Economia Aplicada - Universidade Federal de Viçosa /Bolsista CNPq-Brasil. Email: aredess@yahoo.com.br

3 Doutorando em Economia Aplicada - Universidade Federal de Viçosa /Bolsista CNPq-Brasil. E-mail: matheuswgp@yahoo.com.br

4 Doutorando em Economia Aplicada - Universidade Federal de Viços/Bolsista CNPq-Brasil. E-mail: vladi_fs@yahoo.com.br

5 Doutor em Economia, Professor Adjunto do Departamento de Economia Rural da Universidade Federal de Viçosa. E-mail: mlsantos@ufv.br 


\section{Introdução}

O Brasil é o maior produtor mundial de café, visto que produziu, na safra de 2007/08, cerca de 32.625 mil sacas beneficiadas, sendo $69,04 \%$ da produção de café arábica e 30,96\% de café robusta, tendo o Estado de Minas Gerais, principal produtor nacional, produzido cerca de $45,33 \%$ da safra (CONAB, 2008).

Inserido no agronegócio mundial, o setor cafeeiro é caracterizado pela forte dependência e sensibilidade a fatores naturais e de mercado, tais como produção, preço, taxa de câmbio, consumo, variações climáticas e bianualidade. Tendo em vista que as variáveis citadas acabam influenciando, direta ou indiretamente, os níveis de preço do grão, a produção de café envolve muitas incertezas e riscos, especificamente em relação às flutuações no preço.

Como as receitas e os lucros dos cafeicultores são determinados pelo preço de venda do café, é importante que o produtor, além de planejar a produção, determinando o nível de utilização de insumos - adubos, inseticidas, mão-de-obra, entre outros -, estoque parte da safra, escolhendo o melhor período para venda, com vistas em obter maior retorno financeiro na atividade, desde que a diferença entre o preço na entressafra seja maior que os custos de produção e de estocagem, gerando ainda um nível de prêmio que remunere o agente pela exposição ao risco.

Nesse sentido, este trabalho objetivou avaliar a rentabilidade e o risco na estocagem do café arábica, de modo a fornecer ao cafeicultor, em especial aos produtores da região de Viçosa-MG, medidas de retornos e riscos inerentes à atividade cafeeira. Espera-se que o cafeicultor possa utilizar maiores níveis de insumos na lavoura e estocar parte da produção para venda no período de entressafra, desde que a diferença entre os benefícios monetários gerados seja maior que os custos necessários à promoção e à estocagem. 


\section{Referencial teórico}

\subsection{Avaliação de investimentos}

Entre as etapas de elaboração de projetos destacam-se as análises quantitativas e qualitativas, que resultarão no fluxo de caixa do projeto. A sua correta elaboração é de suma importância, uma vez que os indicadores da rentabilidade e risco do projeto são derivados dele, ou seja, das entradas e saídas de numerários, ocorridas durante o período de vigência do projeto. Os indicadores de viabilidade de investimento utilizados no artigo estão descritos a seguir.

Período de Payback (PP): definido pelo tempo de recuperação do capital investido. O PP é dado por

$$
P P=\sum_{t=0}^{n} L_{t}=0
$$

em que $L_{t}$ é o fluxo líquido do investimento, dado pela diferença entre as entradas e saídas monetárias gerada pelo investimento; $t$, período de tempo; e $n$, tempo-limite. Na sua forma mais simples, a qual é utilizada no trabalho, o PP não leva em consideração o valor do dinheiro ao longo do tempo. Por mensurar o prazo de reembolso do capital investido, o PP é um indicador de liquidez e risco. Assim, quanto menor for o período de recuperação, maior será a liquidez do projeto e menor será o risco do investimento.

De acordo com Woiler e Mathias (1996), esse indicador é, provavelmente, o mais simples de ser obtido. Para Ross et al. (1998), o PP é de fácil entendimento, já que considera as incertezas de fluxos de caixa mais longas e funciona como um ponto de equilíbrio para o investimento. Segundo Buarque (1991) e Ross et al. (1998), a desvantagem do critério 
está no fato de o PP basear-se em um período de tempo-limite, não considerando a vida útil do projeto, ou seja, os fluxos de caixa que virão além do prazo-limite estipulado. Conforme Woiler e Mathias (1996), a sua aplicação ocorre quando as empresas utilizam um prazo-limite para a recuperação de suas despesas e investimentos, sendo aceitos os projetos que possuírem um prazo de reembolso do capital inferior ou igual ao prazo-limite.

Valor Presente Líquido (VPL): é o valor líquido do fluxo de caixa gerado pelo investimento, descontado o valor do dinheiro ao longo do tempo, a uma taxa de desconto predeterminada. Em forma de equação:

$$
V P L=\sum_{t=0}^{n} \frac{L_{4}}{(1+r)^{t}},
$$

em que é o fluxo líquido do investimento, dado pela diferença entre as entradas e saídas monetárias gerada pelo investimento; $t$, período de tempo; n, tempo-limite; e r, taxa de desconto predeterminada. Quando VPL $>0$, o investimento será viável.

Conforme Buarque (1991), uma vantagem da utilização do VPL é que ele informa, em valores atuais, o total dos recursos gerados pelo investimento. Conforme Ross et al. (1998), é o critério de decisão preferível, uma vez que não apresenta deficiências sérias. Além disso, para Ross et al. (1998), em caso de conflito entre os indicadores VPL e TIR, em investimentos mutuamente excludentes, o VPL deve ser o indicador decisivo, pois o investidor está interessado em criar valores monetários.

Taxa Interna de Retorno (TIR): é a taxa de desconto interna gerada pelo investimento que torna o $\mathrm{VPL}=0$, considerando que os fluxos de caixa são reinvestidos pela própria TIR do projeto. Em forma de equação: 
$V P L=\sum_{t=0}^{n} \frac{L_{t}}{\left(1+r^{*}\right)^{t}}=0$

em que $L_{t}$ é o fluxo líquido do investimento, dado pela diferença entre as entradas e saídas monetárias gerada pelo investimento; $t$, período de tempo; n, tempo-limite; e r*, Taxa Interna de Retorno (TIR). Quando a TIR for maior que a taxa de desconto predeterminada, o investimento será viável.

Segundo Ross et al. (1998), a TIR também é de fácil entendimento e transmissão. No entanto, apresenta deficiências, como a possibilidade de obtenção de respostas múltiplas e geração de decisões incorretas em projetos mutuamente excludentes. Para Buarque (1991), a TIR tem a vantagem de ser um indicador gerado pelo próprio investimento, razão por que não necessita de variáveis externas, como a taxa de desconto, no seu cálculo. Além disso, dada a semelhança entre o conceito da TIR com a rentabilidade, $\mathrm{o}$ autor informa que a TIR pode ser comparada com os demais tipos de rentabilidade no mercado, como os de títulos e poupança.

Tendo em vista que se procurou avaliar a eficiência e a competitividade entre sistemas produtivos com diferentes níveis de adoção de insumos na produção, utilizou-se outro indicador no artigo, o Custo Médio (CMe). Entretanto, ao contrário dos indicadores financeiros de investimento (PP, VPL e TIR), o CMe não é obtido a partir do fluxo de caixa, mas a partir dos custos de produção.

Custo Médio (CMe): é o custo de se produzir uma unidade do produto, obtido pela razão:

$C M e=C T / Q$ 
em que CT são os custos totais de produção e q, quantidade produzida. Caso o preço de venda do produto esteja abaixo do $\mathrm{CMe}$, a atividade não remunerará o capital investido.

A vantagem desse indicador, CMe, está em ser de fácil entendimento e servir como parâmetro para análise de eficiência e competitividade entre sistemas. Dados os processos produtivos e os preços iguais entre os produtos, diz-se que o processo produtivo com menor CMe é mais competitivo no mercado, uma vez que esse sistema comporta preços de venda menores do produto.

\subsection{Produção e estocagem}

Como a cultura do café é caracterizada pela produção de uma safra anual, pode-se inferir que, embora o nível de preço flutue, ele apresenta duas características marcantes ao longo do ano: os meses referentes ao período de safra, nos quais o nível de preço fica abaixo do nível médio anual, e os meses que antecedem o período de colheita (entressafra), nos quais o nível de preço fica acima da média anual.

Nesse cenário, a formação de estoque tem o importante papel de amenizar os impactos sazonais, atenuando as diferenças entre oferta e demanda em cada período de tempo e, conseqüentemente, diminuindo a discrepância entre os preços na safra e entressafra, promovendo, com isso, a sua estabilização.

Como destacou Lopes (1983), a diferença entre o preço corrente e o esperado, spread, determina o nível de estoque e a ação especulativa no mercado, de tal forma que a estocagem será viável quando o spread for maior que os custos de estocagem, dado pelo somatório da taxa de juros e os custos diretos da estocagem. Em forma de equação, será viável estocar a produção quando

$\mathrm{PE}-\mathrm{PC}>i+c$, 
em que PE é preço esperado; PC, preço corrente; $i$, custo dos juros; e $c$, custo de estocagem.

Pela equação (6), a viabilidade de estocagem será atrativa quando o spread (PE-PC) for suficiente para cobrir $i$ e $c$, gerando ainda um nível de prêmio que remunere o agente pela exposição ao risco. Dessa forma, a equação conveniente será:

$\mathrm{PE}-\mathrm{PC}=i+c+r$,

em que $r$ é o prêmio do risco, definido por

$r=(\mathrm{PE}-\mathrm{PC})-i-c$.

Se fosse considerado um cenário determinístico desprovido de incertezas, ocorreria o ajuste entre o PE e PC, em que o spread se tornaria igual ao custo de estocagem $i+c$. No entanto, dadas as incertezas, é provável que o spread possa ser maior que o custo $i+c$ e ainda gerar um prêmio de risco $r$, que é de fundamental importância para a tomada de decisão dos agentes, pois, com base nesse valor, os especuladores aumentariam ou diminuiriam as formações dos estoques, de forma que, quanto maior fosse $r$, maior seria o desejo de estocagem e, quanto menor $r$, menor seria o desejo (Lopes, 1983).

Graficamente, a equação de prêmio do risco é exposta na Figura 1, que apresenta uma curva de preços esperados, $\mathrm{PE}$, ao longo do tempo; uma reta representativa do custo de estocagem ${ }^{6}, \mathrm{CE}$; e um preço mínimo $\mathrm{PM}$, que representa o período de safra, ocorrido em $\mathrm{t}_{0}$.

\footnotetext{
6 A utilização de uma reta para representação dos custos de estocagem é apenas uma suposição, dada a presença da taxa de juros (LOPES, 1983). A maneira correta para a sua representação seria uma curva convexa em relação à variável tempo, visto que juros compostos geram retornos exponenciais.
} 


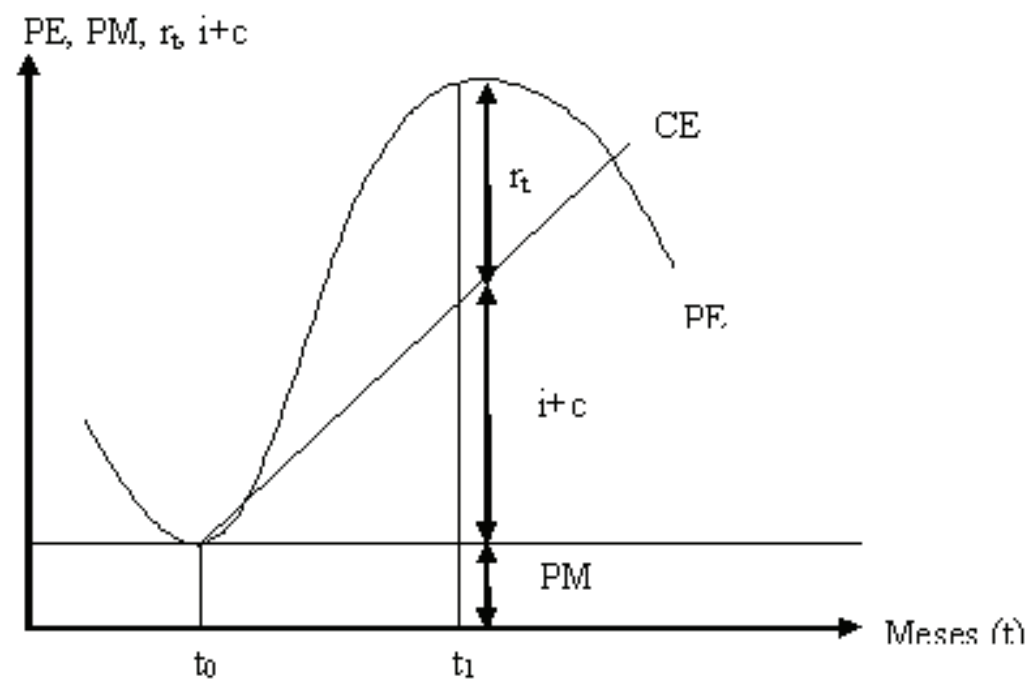

Fonte: Adaptado de Lopes (1983).

Ao plotar a curva de preço esperado, $\mathrm{PE}$, em relação à reta do custo de estocagem no tempo, encontra-se a função do prêmio do risco, que mede o valor do prêmio ao longo do tempo (Figura 2). Por meio dessa função, tem-se uma aproximação da remuneração do risco com um máximo em t (Lopes, 1983), em que t é o melhor período para a venda da safra. 


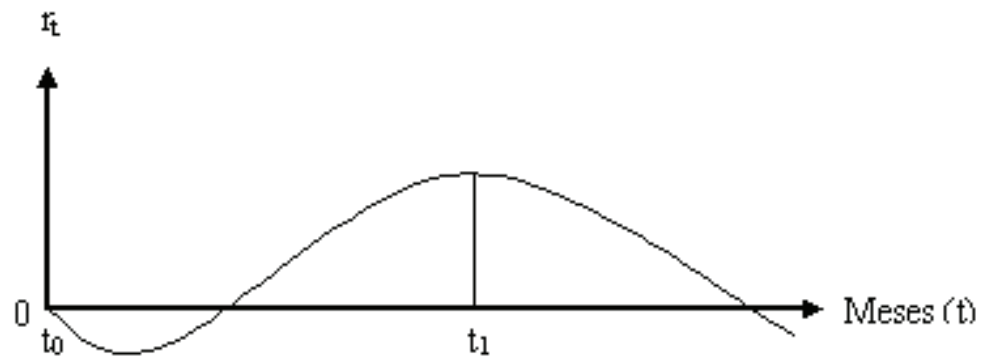

Figura 2 - Função do prêmio do risco.

Fonte: Adaptado de Lopes (1983).

No entanto, quando se consideram as incertezas e as variações nos preços esperados, PE, a função do prêmio do risco torna-se não-determinística, com várias trajetórias, de acordo com as expectativas (Figura 3), o que, de certa forma, torna-o variável, explicado por uma função de probabilidade de preços esperados (Lopes, 1983).

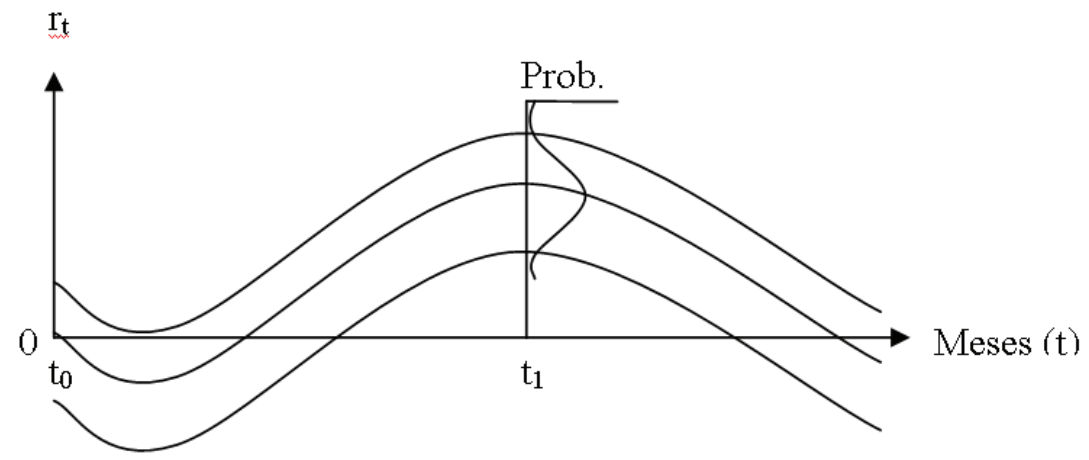

Figura 3 - Variações nas funções do prêmio do risco.

Fonte: Adaptado de Lopes (1983). 


\section{Procedimentos analíticos e fonte de dados}

Elaboraram-se dois fluxos de caixa para a produção de café arábica (Tabelas 1 e 2, Anexas). A vida útil considerada do cafezal foi de 15, em que a primeira safra foi no terceiro ano após implantação da lavoura, a partir dos coeficientes técnicos, preços do café, investimentos e custos de produção e estocagem do café, referentes ao município de ViçosaMG. Os coeficientes técnicos foram obtidos de Arêdes (2006) e, por consulta, de produtores de café no referido município.

O primeiro fluxo de caixa refere-se a um orçamento para produção média anual de 15 sacas na primeira safra e 30 sacas nas demais safras, e o segundo fluxo, a um orçamento para produção média anual de 20 sacas na primeira safra e 40 sacas nas demais. Dessa forma, analisaram-se dois diferentes sistemas produtivos; no segundo sistema foi utilizada a maior aplicação de insumos para elevação do nível da produtividade. A adoção desses dois níveis de produtividade ocorreu pelo fato de querer promover a análise da rentabilidade e risco da estocagem com maior número de sacas de café, o que resulta em maior nível de movimentação financeira.

Os custos diretos de estocagem, $c$, foram iguais a $\mathrm{R} \$ 0,47 / \mathrm{sc}$ ao mês, levantados junto à Incofex Armazenagens Gerais Ltda, e o custo de juros, $i$, obtido pela aplicação da taxa de juros de $6 \%$ ao ano, referente à taxa de juros real paga pela poupança, sobre o CMe, de $\mathrm{R} \$ 255,33$ e R \$ 234,64, que representam os CMe de produção no sistema com 30 e 40 sacas por hectare, respectivamente, obtidos sem considerar o custo de estocagem, e pela utilização do preço médio de $\mathrm{R} \$ 281,64$, referente ao período de 01/1998 e 12/20077. A taxa de juros de $6 \%$ ao ano também foi utilizada para obtenção do VPL. No cálculo da depreciação utilizou-se o método de depreciação linear. Assim, os desgastes dos equipamentos, ferramentas, utensílios e lavoura foram considerados como despesas de

O nível de preço influenciou o CMe, pois se considerou uma alíquota de 2,3\% incidente sobre a receita como representação das despesas com contribuições e impostos. 
Alan Figueiredo de Arêdes, Matheus Wemerson Gomes Pereira,

Vladimir Faria dos Santos \& Maurinho Luiz dos Santos

produção e incorporados nos fluxos de caixa, para obtenção dos indicadores.

Para alcançar o objetivo proposto, foram considerados doze cenários para estocagem e venda do café. Cada um correspondeu a um mês do ano, sendo elaborados 24 fluxos de caixa para retratar os 2 sistemas produtivos com estocagem e venda do café para mês. Em cada cenário utilizaram-se, para o respectivo mês, a média do preço do café e seus custos de estocagem.

Assim, se a safra de café tivesse iniciado em maio e esse mês fosse tomado como base, caso o produtor não vendesse sua produção nesse mês, ele incorreria, além dos custos de produção, em custos de estocagem. Caso o produtor optasse por vendê-la em junho, seriam incluídos em seu fluxo de caixa os custos de estocagem referentes a um mês; alternativamente, se ele escolhesse vendê-la em janeiro do próximo ano, haveria um custo de estocagem correspondente a oito meses.

Na avaliação do nível de risco empregou-se o método de Monte Carlo, utilizando-se como variável aleatória o nível de preço para cada mês, a partir da utilização da distribuição histograma. O software utilizado foi o @ Risk, pela opção de Simulação Alto Stop. Pelo software não se realizava um número de interações predeterminado, mas sim um número de interações necessárias até que a mudança da variável analisada fosse menor que dado valor. No caso do atual trabalho, $1,5 \%$.

Os preços do café referem-se aos valores pagos pela saca de $60 \mathrm{~kg}$ beneficiada de café comum (Tabela 3, Anexo), referentes ao período de 01/1998 a 12/2007 e deflacionados por meio do IGP-DI (COOXUPÉ, 2008). 


\section{Resultados e discussão}

\subsection{Análise sem risco}

Preliminarmente à análise de rentabilidade, obteve-se o Índice Sazonal (IS), dado pela razão entre o preço médio no mês e o preço médio no período de 01/1998 a 12/2007, que foi de $\mathrm{R} \$ 281,64$ por saca. Como visto na Tabela A.3 (Anexo) e na Figura 4, o nível de preço no mês é maior que a média do período analisado, entre os meses de dezembro e maio, sendo o IS maior do que 1, período propício para sua venda, pois, na média, os níveis de preços desses meses são maiores. Por outro lado, o IS foi menor que 1 entre os meses de junho e novembro, o que indica que, nesse período, é menos propícia a realização da venda da safra.

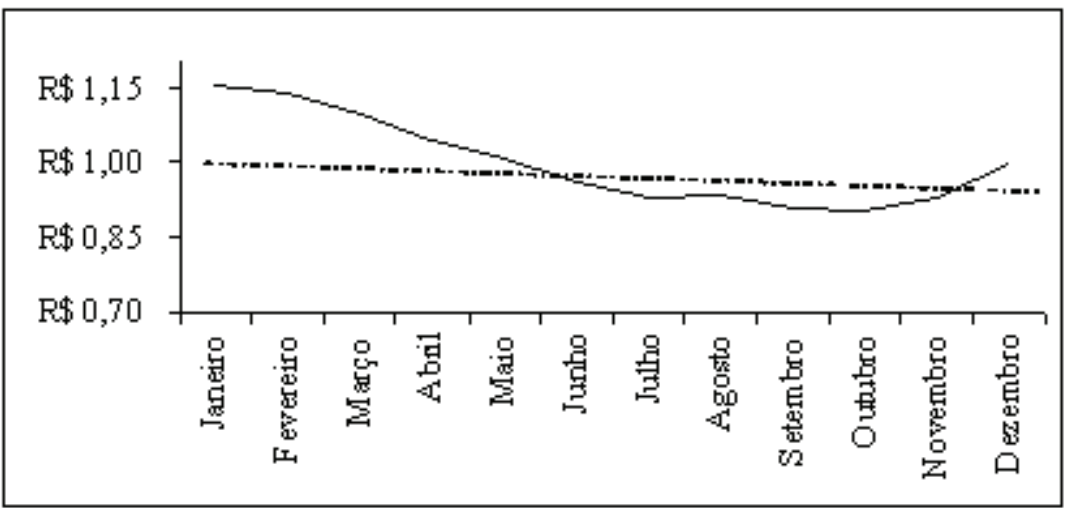

Figura 4 - Indices sazonais do preço do café arábica no período de 01/ 1998 a 12/2007.

Fonte: Dados da pesquisa.

Entretanto, embora tenham sido encontrados maiores níveis de preços nos meses de dezembro a maio, isso não quer dizer, de imediato, que a estocagem do café e sua venda nesse período sejam as decisões mais viáveis, pois devem-se levar em consideração não apenas os níveis de preços, mas também os custos e os riscos de estocagem. 
Alan Figueiredo de Arêdes, Matheus Wemerson Gomes Pereira,

Vladimir Faria dos Santos \& Maurinho Luiz dos Santos

Dessa forma, analisaram-se doze cenários, utilizando-se nos fluxos de caixa a média do preço do café do respectivo mês, verificada entre 01/ 1998 e 12/2007, e o custo de produção e de estocagem do café até sua venda. Em seguida, calcularam-se os indicadores financeiros para os dois sistemas produtivos, nos doze cenários. Os resultados são vistos na Tabela 4.

Tabela 4 - Indicadores financeiros para os dois sistemas produtivos, nos 12 cenários de estocagem de café arábica, Viçosa-MG

\begin{tabular}{|c|c|c|c|c|c|c|c|c|}
\hline \multirow[t]{2}{*}{ Cenários } & \multicolumn{4}{|c|}{ Produção e es tocagem de 30 sc/ha } & \multicolumn{4}{|c|}{ Produção e estocagem de 40 sc/há } \\
\hline & $\mathrm{CMe}$ & PP & VPL & TIR & CMe & PP & VPL & TIR \\
\hline Janeiro & 270,30 & $8, \pi$ & 7400,56 & 11,63 & 248,78 & 6,92 & 18380,51 & 17,52 \\
\hline Fevereiro & 271,94 & 9,28 & 5798,58 & 10,49 & 250,32 & 7,20 & 16278,97 & 16,37 \\
\hline Marp̧o & 273,42 & 10,60 & 2581,36 & 8,07 & 251,70 & 7,92 & 12023,79 & 13,93 \\
\hline Abril & 274,83 & 13,20 & $-1450,08$ & 4,77 & 253,00 & 9,19 & 6682,98 & 10,63 \\
\hline Maio & 255,39 & 11,47 & 969,87 & 6,80 & 234,70 & 8,45 & 9530,69 & 12,43 \\
\hline Junho & 256,84 & 14,36 & $-2681,49$ & 3,69 & 236,04 & 9,83 & 4696,66 & 06,58 \\
\hline Julho & 258,34 & 15,71 & $-5643,25$ & 0,89 & 237,45 & 11,54 & 782,09 & 06,58 \\
\hline Agosto & 260,15 & 15,67 & $-5509,54$ & 1,02 & 239,14 & 11,42 & 994,81 & 06,73 \\
\hline Setembro & 261,74 & 17,19 & $-7571,99$ & $-1,10$ & 240,63 & 13,12 & $-1720,68$ & 04,69 \\
\hline Outub ro & 263,45 & 17,50 & $-8385,50$ & $-1,99$ & 242,24 & 13,96 & $-2770,91$ & 03,86 \\
\hline Novembro & 265,37 & 16,91 & $-6997,19$ & $-0,49$ & 244,06 & 12,53 & $-885,39$ & 05,33 \\
\hline Dezembro & 267,53 & 14,77 & $-3060,82$ & 3,34 & 246,11 & 9,94 & 4397,55 & $0 \theta, 12$ \\
\hline Média & 264,94 & 13,79 & $-2045,79$ & 3,93 & 243,68 & 10,17 & 5699,25 & 9,48 \\
\hline
\end{tabular}

Fonte: Resultados da pesquisa.

Evidencia-se, pela Tabela 4, que o mês que teve o menor CMe de produção foi o mês de maio, de $\mathrm{R} \$ 255,39$ e $\mathrm{R} \$ 234,70$ no sistema com produção e venda de $30 \mathrm{sc} / \mathrm{ha}$ e $40 \mathrm{sc} / \mathrm{ha}$, pois nesse mês não foram considerados os custos de estocagem. Além disso, as diferenças entre os $\mathrm{CMe}$, entre os meses, devem-se não apenas aos custos ocasionados pela estocagem, armazenagem e juros, mas também aos custos provenientes das contribuições e impostos. Os custos com contribuições e impostos foram considerados como $2,3 \%$ da receita obtida. Ressalta- 
se também que o investimento ou dispêndio monetário, realizado para aquisição da terra para implantação do cafezal, não foi incluído no CMe de produção, uma vez que se consideraram a venda da terra e o reembolso do seu investimento no fluxo de caixa, no mesmo valor, no final do ciclo da atividade.

Em relação ao tempo de recuperação do capital investido, a venda da safra em janeiro proporcionou o menor tempo, apresentado um PP de 8,77 e 6,92 anos para o sistema com produção e venda de $30 \mathrm{sc} / \mathrm{ha}$ e 40 sc/ha, respectivamente. Por meio dos indicadores de viabilidade VPL e TIR (Tabela 4), é possível verificar que a estocagem do café é uma estratégia financeiramente viável, sendo o mês de janeiro o mais propício à venda do café, pois apresentou o maior VPL e a maior TIR, entre todos os meses, iguais a $\mathrm{R} \$ 7400,56$ e $11,63 \%$ ao ano, quando produzidas e vendidas $30 \mathrm{sc} / \mathrm{ha}$, e de $\mathrm{R} \$ 18380,51$ e 17,52\% ao ano, quando produzidas e vendidas $40 \mathrm{sc} / \mathrm{ha}$ de café.

Esse resultado indica que o produtor poderia estocar pelo menos parte da sua safra por oito meses, considerando a sua produção em maio, e vendê-la em janeiro, para obter um maior retorno financeiro, visto que os maiores níveis de preços na entressafra cobrem os custos de produção e de estocagem e ainda geram maior lucro para o cafeicultor.

Pela análise dos resultados da Tabela 4, evidencia-se que a elevação da produtividade aumentou significativamente, o retorno financeiro na produção do café. Em todos os meses, o maior nível de retorno financeiro, medido pelo VPL e TIR, sempre foi maior para a produção e para a venda de $40 \mathrm{sc} / \mathrm{ha}$. Em termos médios, enquanto a produção e venda de $30 \mathrm{sc} /$ ha promoveu um VPL de R - 2045,79 e uma TIR de 3,93\% ao ano, a produção e a venda de $40 \mathrm{sc} /$ ha promoveram um VPL de R $\$$ 5699,25 e uma TIR de 9,48\% ao ano, o que indica que a produção do café é, em termos médios, financeiramente viável, uma vez que o VPL foi positivo e a TIR foi maior que a taxa de desconto, ou juros, de $6 \%$ ao ano na média. 
Os dados contidos na Tabela 4 também são apresentados na Figura 5, que demonstra a evolução dos indicadores VPL e TIR ao longo dos meses de estocagem e indica, mais uma vez, a importância da elevação na produtividade e da estocagem para a rentabilidade da atividade, estando os melhores meses para a venda concentrados no período anterior à safra, especialmente nos meses de janeiro, fevereiro e março, e os piores meses, entre junho e novembro (Figura 5).

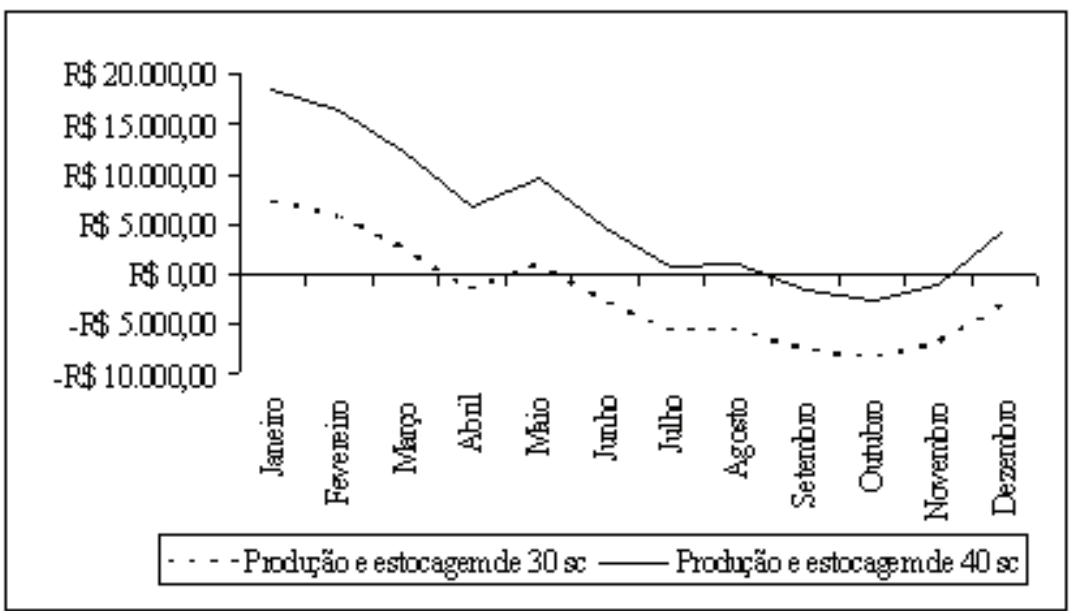

Figura 5 - Valor Presente Líquido (VPL) obtido para produção e venda do café arábica, nos 12 cenários, Viçosa-MG

Fonte: Resultados da pesquisa.

\subsection{Análise com risco}

Em relação à análise da rentabilidade sob condição de risco, foram obtidas as distribuições de probabilidade de ocorrência dos indicadores VPL e TIR, a partir do método de Monte Carlo, e diferentes níveis de preço e diferentes valores para VPL e TIR, para cada cenário e sistema produtivo. 
De acordo com os resultados (Tabela 5), janeiro, fevereiro e março foram os meses que tiveram as maiores probabilidades de gerarem VPL positivo e TIR maior que a taxa de juros de $6 \%$ ao ano. No mês de janeiro, observa-se que houve $65 \%$ de probabilidade de o VPL ser positivo e $75 \%$ de a TIR ser maior que a taxa de juros de $6 \%$ ao ano, no sistema com produção e estocagem de $30 \mathrm{sc} / \mathrm{ha}$. No sistema com produção e estocagem de $40 \mathrm{sc} / \mathrm{ha}$, as probabilidades elevaram-se para $80 \%$ a $85 \%$.

Tabela 5 - Probabilidade de ocorrência dos indicadores financeiros nos dois sistemas produtivos, nos 12 cenários de estocagem do café arábica, Viçosa-MG

\begin{tabular}{|c|c|c|c|c|}
\hline \multirow[t]{2}{*}{ Cenários } & \multicolumn{2}{|c|}{$\begin{array}{c}\text { Produção e estocagem } \\
\text { de } 30 \text { sc/ha }\end{array}$} & \multicolumn{2}{|c|}{$\begin{array}{c}\text { Produção e estocagem } \\
\text { de } 40 \mathrm{sc} / \mathrm{ha}\end{array}$} \\
\hline & $\mathrm{VPL}^{*}>0$ & $\operatorname{TIR}^{* *}>r$ & $\mathrm{VPL}^{*}>0$ & $\mathrm{TIR}^{* *}>r$ \\
\hline Janeiro & $65 \%$ & $75 \%$ & $80 \%$ & $85 \%$ \\
\hline Fevereiro & $60 \%$ & $70 \%$ & $70 \%$ & $80 \%$ \\
\hline Março & $50 \%$ & $65 \%$ & $65 \%$ & $70 \%$ \\
\hline Abril & $50 \%$ & $55 \%$ & $65 \%$ & $70 \%$ \\
\hline Maio & $40 \%$ & $60 \%$ & $45 \%$ & $60 \%$ \\
\hline Junho & $50 \%$ & $65 \%$ & $60 \%$ & $70 \%$ \\
\hline Julho & $30 \%$ & $50 \%$ & $40 \%$ & $55 \%$ \\
\hline Agosto & $25 \%$ & $40 \%$ & $45 \%$ & $65 \%$ \\
\hline Setembro & $25 \%$ & $40 \%$ & $50 \%$ & $70 \%$ \\
\hline Outubro & $35 \%$ & $55 \%$ & $50 \%$ & $65 \%$ \\
\hline Novembro & $45 \%$ & $60 \%$ & $55 \%$ & $70 \%$ \\
\hline Dezembro & $60 \%$ & $75 \%$ & $75 \%$ & $80 \%$ \\
\hline Média & $45 \%$ & $59 \%$ & $58 \%$ & $70 \%$ \\
\hline
\end{tabular}


Em contraposição, os meses que apresentaram os menores níveis de probabilidade na geração de VPL e TIR, em ambos os sistemas produtivos, foram os meses de junho e novembro. Assim, por exemplo, no mês de agosto houve $25 \%$ de probabilidade de o VPL ser positivo e $40 \% "$ de probabilidade de a TIR ser maior que a taxa de juros de $6 \%$ ao ano, no sistema com produção e estocagem de $30 \mathrm{sc}$; e $45 \%$ e $65 \%$ de probabilidade, respectivamente, no sistema com produção e estocagem de $40 \mathrm{sc}$. Em termos médios, houve $45 \%$ e $59 \%$ de probabilidade de o VPL e de a TIR indicarem viabilidade financeira na produção e estocagem de 30 sc de café e $58 \%$ e $70 \%$, respectivamente, na produção e estocagem de $40 \mathrm{sc}$ (Tabela 5 e Figura 6).

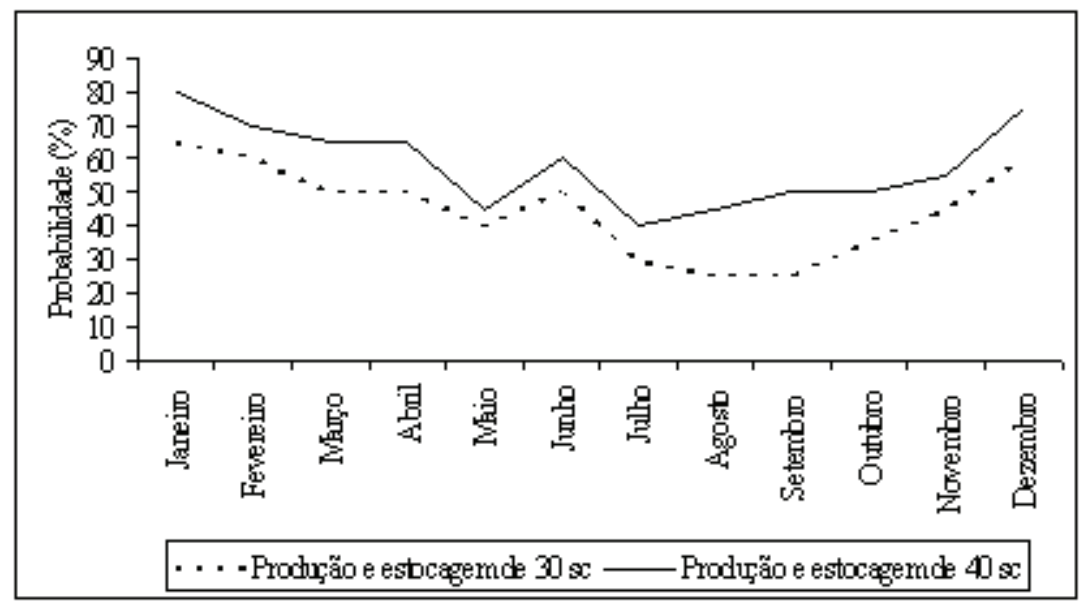

Figura 6 - Nível de probabilidade de o Valor Presente Líquido (VPL) ser positivo para produção e venda do café arábica, nos 12 cenários, Viçosa-MG.

Fonte: Resultados da pesquisa. 


\section{Conclusão}

Dada a importância do planejamento da empresa agrícola, o presente trabalho objetivou avaliar a rentabilidade e risco na estocagem do café arábica pelos produtores da região de Viçosa-MG, além de informar ao cafeicultor sobre os efeitos da utilização de insumos na lavoura e escolha do período do ano mais propício à venda da produção, de modo a garantir maiores retornos e menores riscos sobre o investimento.

Para isso, obtiveram-se coeficientes técnicos, preços do café, investimentos e custos de produção e estocagem para elaboração dos fluxos de caixa para produção de café em dois sistemas produtivos, um com baixa produtividade e outro com alta produtividade, e doze cenários para a estocagem e venda do café, cada um representando um mês do ano. Em seguida, foram obtidos os indicadores financeiros Custo Médio (CMe), Período de Payback (PP), Valor Presente Líquido (VPL) e Taxa Interna de Retorno (TIR).

De acordo com os resultados, a elevação da produtividade pela adoção de maiores níveis de insumos (adubos, inseticidas, mão-de-obra, entre outros) promove significativa diminuição do $\mathrm{CMe}$ de produção e do $\mathrm{PP}$, assim como elevação da rentabilidade do investimento na produção do café, uma vez que os indicadores VPL e TIR sempre foram maiores para produção e estocagem de $40 \mathrm{sc} / \mathrm{ha}$ do que para a produção e estocagem de $30 \mathrm{sc} / \mathrm{ha}$, independentemente do mês considerado para a venda do café.

Com relação à análise da viabilidade financeira da estocagem, os resultados indicam que a estocagem é viável na maioria dos meses no sistema com produção e estocagem de $40 \mathrm{sc}$, quais sejam, janeiro, fevereiro, março, abril, maio, junho, julho, agosto e dezembro, enquanto no sistema com produção e estocagem de $30 \mathrm{sc}$, a estocagem é viável apenas nos meses de janeiro, fevereiro, março e maio. Em ambos os sistemas produtivos, os melhores meses para a venda são concentrados no período anterior à safra, especialmente nos meses de janeiro, fevereiro 
Alan Figueiredo de Arêdes, Matheus Wemerson Gomes Pereira,

Vladimir Faria dos Santos \& Maurinho Luiz dos Santos

e março, e os piores, entre junho e novembro. Além disso, a comercialização no período de entressafra resulta nas maiores probabilidades de gerar indicadores econômicos favoráveis à atividade, VPL positivo e TIR maior que a taxa de juros.

Em síntese, conclui-se que a estocagem do café é uma estratégia financeiramente viável. Além disso, a elevação da produtividade do cafezal pela adoção de maior quantidade de insumos é um fator condicionante tanto para elevação do nível de rentabilidade quanto para diminuição do nível de risco da atividade, pois as entradas monetárias ou benefícios financeiros ocasionados pela elevação da produtividade são maiores que os custos e investimentos necessários para elevação da produção.

\section{Referências}

ARÊDES, A. F. Avaliação econômica da irrigação do cafeeiro em uma região tradicionalmente produtora. $89 \mathrm{f}$. Dissertação (Mestrado em Economia Aplicada). Universidade Federal de Viçosa, Viçosa, MG, 2006.

BUARQUE, C. Avaliação econômica de projetos: uma apresentação didática. $8^{\mathrm{a}}$ ed. Rio de Janeiro: Campus, 1991. 266 p.

CONAB. Companhia Nacional de Abastecimento. Central de informações agropecuárias. Disponível em: <http://www.conab.gov.br/ conabweb/download/safra/3_levantamento_200708.pdf> Acesso em: 12 fev. 2008.

COOPERATIVA REGIONAL DE CAFEICULTORES DE GUAXUPÉ - COOXUPÉ. Disponível em: < https://www.cooxupe.com.br>Acesso em: 22 fev. 2008. 
LOPES, R. M. Formação e estabilização dos preços agrícolas. A especulação nos mercados agrícolas e formação de renda do produtor. Ministério da agricultura (Companhia de financiamento da produção), Coleção análise e pesquisa, vol. 28, Brasília, Agosto de 1983.

\section{ROSS, S. A.; WESTERFIELD, R. W.; JORDAN, B. D. Princípios de administração financeira. $2^{\mathrm{a}}$ ed. São Paulo: Atlas, 1998. 425 p.}

WOILER, S.; MATHIAS, W. F. Projetos: planejamento, elaboração e análise. São Paulo: Atlas, 1996. 294 p.

\footnotetext{
Abstract - The objective of this article was to evaluate the yield and risk in the production and storage of the Arabian coffee. Cash flows are elaborated for coffee production in two productive systems, one with low productivity and other with high productivity. Twelve different scenarios are simulated, each one representing the returns and risks in the production and storage for every month of the year. The financial indicators Payback Period (PP), Net Present Value (VPL) and Internal Rate of Return (TIR) and the indicator Average Cost $(\mathrm{CMe})$, suggest that high productivity is important to increase profitability and to decrease the activity risk, being the best periods to sale coffee, on the part of the producers, the months that precede the harvest, January, February and March.

Keywords: coffee, return, risk.
} 
Alan Figueiredo de Arêdes, Matheus Wemerson Gomes Pereira, Vladimir Faria dos Santos \& Maurinho Luiz dos Santos

\section{Anexo}

Tabela A.1: Fluxo de caixa elaborado para produção e estocagem de 30 sc/há, no mês de janeiro, Viçosa-MG

\begin{tabular}{|c|c|c|c|c|c|c|c|c|c|}
\hline Descrição & E.S. & V.U. & Q. & Ano 0 & Ano 1 & Ano 2 & Ano 3 & $\ldots$ & Ano 15 \\
\hline A- Entradas & & & & & & 4872,41 & 9744,82 & $\cdots$ & 9744,82 \\
\hline Receita & $\mathrm{R} \$$ & & & & & & & $\cdots$ & \\
\hline Produção & $\mathrm{Sc}$ & & & & & 15,00 & 30,00 & $\cdots$ & 30,00 \\
\hline Preço & $\mathrm{R} \$$ & & & & & 324,83 & 324,83 & $\cdots$ & 324,83 \\
\hline Valor residual líquido & $\mathrm{R} \$$ & & & & & & & $\cdots$ & 500,00 \\
\hline B-Saídas & & & & & 3555,93 & 5918,85 & 7173,52 & $\cdots$ & 7173,52 \\
\hline 1. Insumos e materiais & & & & & & & & $\cdots$ & \\
\hline Calcário & $\mathrm{R} \$ /$ ton & 36,00 & 2 & & 72,00 & 72,00 & 72,00 & $\cdots$ & 72,00 \\
\hline Ácido bórico & $\mathrm{R} \$ / \mathrm{kg}$ & 1,80 & 15 & & 27,00 & 27,00 & 27,00 & $\cdots$ & 27,00 \\
\hline Sulfato de zinco & $\mathrm{R} \$ / \mathrm{kg}$ & 1,79 & 4 & & 7,16 & 7,16 & 7,16 & $\cdots$ & 7,16 \\
\hline Formulato $20-05-20$ & $\mathrm{R} \$ / \mathrm{kg}$ & 1,15 & 14 & & 1610,00 & 1610,00 & 1610,00 & $\cdots$ & 1610,00 \\
\hline Herbicida & $\mathrm{R} \$ /$ lit & 12,80 & 1 & & 12,80 & 12,80 & 12,80 & $\cdots$ & 12,80 \\
\hline Inseticida & $\mathrm{R} \$ /$ lit & 22,93 & 2 & & 45,86 & 45,86 & 45,86 & $\ldots$ & 45,86 \\
\hline Fungicida (Ox. Cobre + sist.) & $\mathrm{R} \$ / \mathrm{kg}$ & 33,00 & 5 & & 165,00 & 165,00 & 165,00 & $\cdots$ & 165,00 \\
\hline Fung. + inset. (Granulado) & $\mathrm{R} \$ / \mathrm{kg}$ & 12,00 & 15 & & 180,00 & 180,00 & 180,00 & $\cdots$ & 180,00 \\
\hline Sacarias & $\mathrm{R} \$ / \mathrm{Sc}$ & 3,20 & Sc & & & 48,00 & 96,00 & $\cdots$ & 96,00 \\
\hline 2. Manutenção & & & & & & & & $\cdots$ & \\
\hline Capina & HD & 18,50 & 18 & & 333,00 & 333,00 & 333,00 & $\cdots$ & 333,00 \\
\hline Desbrota & HD & 18,50 & 5 & & 92,50 & 92,50 & 92,50 & $\cdots$ & 92,50 \\
\hline Calagem & $\mathrm{HM}$ & 37,28 & 2 & & 100,66 & 100,66 & 100,66 & $\cdots$ & 100,66 \\
\hline Calagem & HD & 18,50 & 2 & & 37,00 & 37,00 & 37,00 & $\cdots$ & 37,00 \\
\hline Adubação manual & HD & 18,50 & 4 & & 88,80 & 88,80 & 88,80 & $\cdots$ & 88,80 \\
\hline Aplicação defensivo manual & HD & 18,50 & 6 & & 116,55 & 116,55 & 116,55 & $\cdots$ & 116,55 \\
\hline Aplicação Herbicida & $\mathrm{HM}$ & 34,22 & 2 & & 99,24 & 99,24 & 99,24 & $\cdots$ & 99,24 \\
\hline Cerca m-d-o e material & $\mathrm{R} \$$ & & & & 103,00 & 103,00 & 103,00 & $\cdots$ & 103,00 \\
\hline 3. Colheita & & & & & & & & $\cdots$ & \\
\hline Colheita & $\mathrm{R} \$ / \mathrm{sc}$ & 56,00 & & & & 840,00 & 1680,00 & $\cdots$ & 1680,00 \\
\hline Secagem & HD & 18,50 & 7 & & & 133,20 & 133,20 & $\cdots$ & 133,20 \\
\hline Arruação/ Esparração & HD & 18,50 & 15 & & & 277,50 & 277,50 & $\cdots$ & 277,50 \\
\hline Beneficiamento & $\mathrm{R} \$ / \mathrm{sc}$ & 3,00 & $\mathrm{Sc}$ & & & 45,00 & 90,00 & $\cdots$ & 90,00 \\
\hline Transporte interno & HM & 31,78 & 2 & & & 63,56 & 63,56 & $\cdots$ & 63,56 \\
\hline Utensílios para colheita & $\mathrm{R} \$$ & & & & & 317,00 & 317,00 & $\cdots$ & 317,00 \\
\hline Armazenagem & $\mathrm{R} \$ / \mathrm{sc}$ & 13,97 & $\mathrm{Sc}$ & & & 209,60 & 419,20 & $\cdots$ & 419,20 \\
\hline Depreciação & & & & & 315,37 & 632,37 & 632,37 & $\cdots$ & 632,37 \\
\hline Contribuições/Impostos & $\mathrm{R} \$$ & $2,3 \%$ & Receita & & & 112,07 & 224,13 & $\cdots$ & 224,13 \\
\hline Administração & $\mathrm{R} \$$ & 150,00 & 1 & & 150,00 & 150,00 & 150,00 & $\cdots$ & 150,00 \\
\hline C- Lucro Líquido & & & & & $-3555,93$ & $-1046,44$ & 2571,30 & $\cdots$ & 2571,30 \\
\hline D- Investimento inicial* & $\mathrm{R} \$$ & & & $-6741,43$ & & & & $\cdots$ & \\
\hline \multirow[t]{2}{*}{ E- Investimento em terra } & $\mathrm{R} \$$ & & & $-3500,00$ & & & & $\cdots$ & 3500,00 \\
\hline & & & & $\begin{array}{c}- \\
10241,4 \\
3 \\
\end{array}$ & $-3555,93$ & $-1046,44$ & 2571,30 & $\cdots$ & 6571,30 \\
\hline F- Fluxo Líquido do Caixa & & & & $\begin{array}{c}- \\
10241,4\end{array}$ & & & & $\cdots$ & \\
\hline G- Fluxo Líquido Acumulado & $\mathrm{R} \$$ & & & 3 & $-13797,36$ & $-14843,81$ & $-12272,50$ & & 22583,12 \\
\hline
\end{tabular}

ES: Especificação. VU: Valor Unitário. Q: Quantidade. HD: Homem-Dia. HM: Hora-Máquina. Sc: Saca de café de $60 \mathrm{~kg}$ beneficiada.

*Aração, calagem, gradeação, conservação do solo, dessecação com herbicida, sulcação, distribuição calcários nos sulcos, distribuição de fertilizantes,

incorporação de adubo no sulco, transporte das mudas, plantio, replantio, superfosfato simples, nitrato de amônia, ácido bórico mais cloreto de potássio,

oxicloreto de cobre, utensílios e ferramentas, cerca, mudas, outros.

Fonte: Resultados da pesquisa. 
REVISTA DE ECONOMIA E AGRONEGÓCIO, VOL.6, $N^{o} 2$

Tabela A.2: Fluxo de caixa elaborado para produção e estocagem de 40 schh́, no mês de janeiro, Viçosa-MG

\begin{tabular}{|c|c|c|c|c|c|c|c|c|c|}
\hline Descrição & E.S. & V.U. & Q. & Ano 0 & Ano 1 & Ano 2 & Ano 3 & $\ldots$ & Ano 15 \\
\hline A- Entradas & & & & & & 6496,55 & 12993,09 & $\ldots$ & 12993,09 \\
\hline Receita & RS & & & & & & & $\ldots$ & \\
\hline Produção & $\mathrm{Sc}$ & & & & & 20,00 & 40,00 & $\ldots$ & 40,00 \\
\hline Preço & $\mathrm{RS}$ & & & & & 324,83 & 324,83 & $\ldots$ & 324,83 \\
\hline Valor residual líquido & $\mathrm{RS}$ & & & & & & & $\ldots$ & 500,00 \\
\hline B-Saídas & & & & & 4404,74 & 7201,11 & 8857,45 & $\ldots$ & 8857,45 \\
\hline 1. Insumos e materiais & & & & & & & & $\ldots$ & \\
\hline Calcário & $\mathrm{R} \$$ /ton & 36,00 & 3 & & 108,00 & 108,00 & 108,00 & $\ldots$ & 108,00 \\
\hline Ácido bórico & $\mathrm{RS} / \mathrm{kg}$ & 1,80 & 30 & & 54,00 & 54,00 & 54,00 & $\ldots$ & 54,00 \\
\hline Sulfato de zinco & $\mathrm{RS} / \mathrm{kg}$ & 1,79 & 5 & & 8,95 & 8,95 & 8,95 & $\cdots$ & 8,95 \\
\hline Formulato 20-05-20 & $\mathrm{RS} / \mathrm{kg}$ & 1,15 & 1800 & & 2070,00 & 2070,00 & 2070,00 & $\cdots$ & 2070,00 \\
\hline Herbicida & $\mathrm{RS} / \mathrm{lit}$ & 12,80 & 3 & & 38,40 & 38,40 & 38,40 & $\cdots$ & 38,40 \\
\hline Inseticida & $\mathrm{R} \$ /$ lit & 22,93 & 1 & & 22,93 & 22,93 & 22,93 & $\ldots$ & 22,93 \\
\hline Fungicida (Ox. Cobre + sist.) & $\mathrm{R} \$ / \mathrm{kg}$ & 33,00 & 6 & & 198,00 & 198,00 & 198,00 & $\cdots$ & 198,00 \\
\hline Fung. + inset. (Granulado) & $\mathrm{RS} / \mathrm{kg}$ & 12,00 & 25 & & 300,00 & 300,00 & 300,00 & $\ldots$ & 300,00 \\
\hline Sacarias & $\mathrm{RS} / \mathrm{Sc}$ & 3,20 & $\mathrm{Sc}$ & & & 64,00 & 128,00 & $\ldots$ & 128,00 \\
\hline 2. Manutenção & & & & & & & & $\ldots$ & \\
\hline Capina & $\mathrm{HD}$ & 18,50 & 18 & & 333,00 & 333,00 & 333,00 & $\ldots$ & 333,00 \\
\hline Desbrota & $\mathrm{HD}$ & 18,50 & 13,9 & & 257,15 & 257,15 & 257,15 & $\ldots$ & 257,15 \\
\hline Calagem & HM & 37,28 & 2,7 & & 100,66 & 100,66 & 100,66 & $\ldots$ & 100,66 \\
\hline Calagem & $\mathrm{HD}$ & 18,50 & 2,2 & & 40,70 & 40,70 & 40,70 & $\cdots$ & 40,70 \\
\hline Adubação manual & $\mathrm{HD}$ & 18,50 & 4,8 & & 88,80 & 88,80 & 88,80 & $\ldots$ & 88,80 \\
\hline Adubação mecanizada & & & & & & & & $\ldots$ & \\
\hline Aplicaçao defensivo manual & $\mathrm{HD}$ & 18,50 & 6,3 & & 116,55 & 116,55 & 116,55 & $\ldots$ & 116,55 \\
\hline Aplicação Herbicida & HM & 34,22 & 2,9 & & 99,24 & 99,24 & 99,24 & $\ldots$ & 99,24 \\
\hline Cerca m-d-o e material & $\mathrm{R} \$$ /ha. & & & & 103,00 & 103,00 & 103,00 & $\ldots$ & 103,00 \\
\hline 3. Colheita & & & & & & & & $\ldots$ & \\
\hline Colheita & $\mathrm{RS} / \mathrm{sc}$ & 56,00 & & & & 1120,00 & 2240,00 & $\ldots$ & 2240,00 \\
\hline Secagem & $\mathrm{HD}$ & 18,50 & 7,2 & & & 133,20 & 133,20 & $\ldots$ & 133,20 \\
\hline Arruação/ Esparração & $\mathrm{HD}$ & 18,50 & 15 & & & 277,50 & 277,50 & $\ldots$ & 277,50 \\
\hline Beneficiamento & $\mathrm{RS} / \mathrm{sc}$ & 3,00 & $\mathrm{Sc}$ & & & 60,00 & 120,00 & $\ldots$ & 120,00 \\
\hline Transporte interno & $\mathrm{HM}$ & 31,78 & 3 & & & 95,34 & 95,34 & $\cdots$ & 95,34 \\
\hline Utensílios para colheita & $\mathrm{RS}$ & & & & & 317,00 & 317,00 & $\cdots$ & 317,00 \\
\hline Armazenagem & $\mathrm{RS} / \mathrm{sc}$ & 13,15 & $\mathrm{Sc}$ & & & 262,91 & 525,82 & $\ldots$ & 525,82 \\
\hline Depreciação & & & & & 315,37 & 632,37 & 632,37 & $\ldots$ & 632,37 \\
\hline Contribuições/Impostos & $\mathrm{RS}$ & $2,3 \%$ & Receita & & & 149,42 & 298,84 & $\cdots$ & 298,84 \\
\hline Administração & RS & 150,00 & 1 & & 150,00 & 150,00 & 150,00 & $\ldots$ & 150,00 \\
\hline C- Lucro Líquido & & & & & $-4404,74$ & $-704,57$ & 4135,65 & $\ldots$ & 4135,65 \\
\hline D- Investimento inicial* & RS & & & $-7590,24$ & & & & $\ldots$ & \\
\hline E- Investimento em terra & RS & & & $-3500,00$ & & & & $\ldots$ & 3500,00 \\
\hline F- Fluxo Líquido do Caixa & & & & $-11090,24$ & $-4404,74$ & $-704,57$ & 4135,65 & $\cdots$ & 8135,65 \\
\hline G- Fluxo Líquido Acumulado & $\mathrm{RS}$ & & & $-11090,24$ & $-15494,98$ & $-16199,55$ & $-12063,90$ & $\cdots$ & 41563,86 \\
\hline
\end{tabular}


Alan Figueiredo de Arêdes, Matheus Wemerson Gomes Pereira, Vladimir Faria dos Santos \& Maurinho Luiz dos Santos

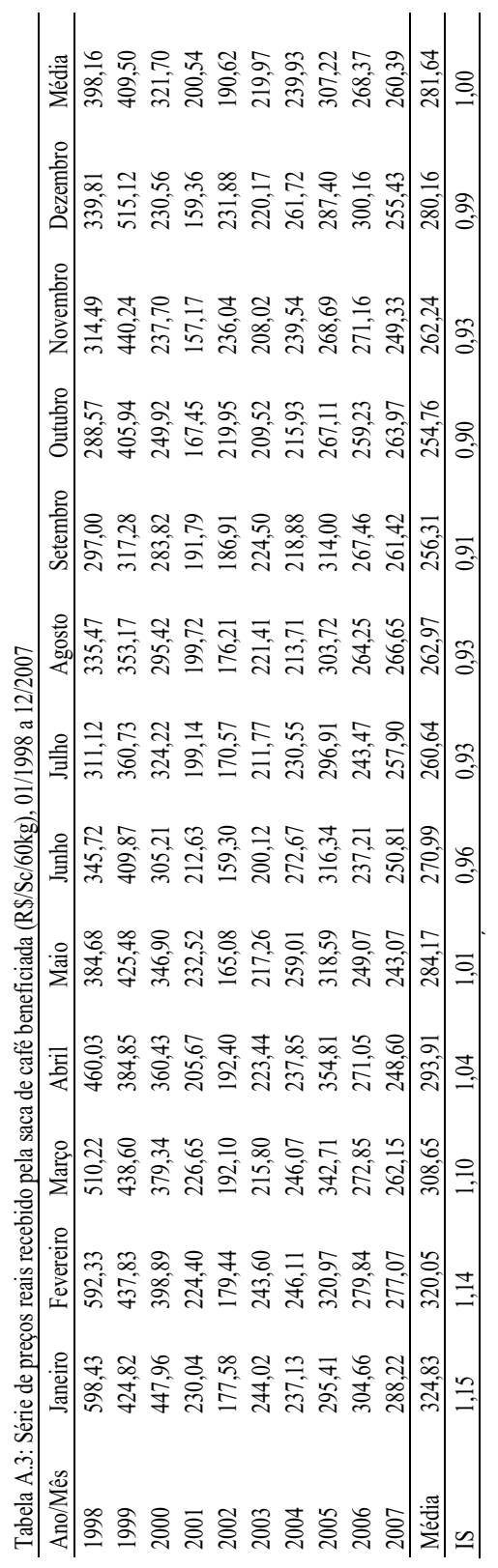


REVISTA DE ECONOMIA E AGRONEGÓCIO, VOL.6, $N^{\circ} 2$ 